\title{
Perfil e percepções de homens obesos mórbidos cearenses sobre a vida obesa
}

\author{
Profile and perceptions of morbid obese Ceará men \\ about obese life
}

\author{
Francisco Ricardo Miranda Pinto', Carlos Antônio Bruno da Silva \\ 1Autor para correspondência. Universidade de Fortaleza, Universidade Estadual Vale do Acaraú, Centro Universitário INTA. \\ Fortaleza, Ceará, Brasil. ORCID: 0000-0003-0771-6266. ricardomiranda195@gmail.com \\ 2Universidade de Fortaleza, Secretaria da Saúde do Estado do Ceará. Fortaleza, Ceará, Brasil. ORCID: 0000-0002-2968-9206. carlosbruno@unifor.br
}

\begin{abstract}
RESUMO | A vivência da obesidade mórbida é a temática central deste estudo que tem como objetivo traçar o perfil e as percepções do homem obeso mórbido cearense sobre a vida obesa e suas nuances tendo como suporte as diretrizes da Associação Brasileira de Estudos da Obesidade e Síndrome Metabólica (ABESO) e a Fenomenologia da Percepção de Merleau-Ponty (2011). Estudo de abordagem qualitativa, com lente fenomenológica, desenvolvido em uma unidade hospitalar de referência em obesidade de Fortaleza-Ceará, com dezessete homens obesos mórbidos cujo critério de seleção foi ter Índice de Massa Corporal (IMC) $>30 \mathrm{~kg} / \mathrm{m}^{2}$ com comorbidades ou $>40 \mathrm{~kg} / \mathrm{m}^{2}$ sem comorbidades e de exclusão a desorientação temporal ao assinar o Termo de Consentimento Livre e Esclarecido (TCLE). A coleta de dados utilizou como protocolo de pesquisa a Entrevista Fenomenológica em Profundidade enquanto o tratamento e a análise dos dados foram realizados na perspectiva da Teoria da Fenomeologia da Percepção de Merleau-Ponty, respeitando a Resolução $466 / 2012$. Os resultados apontam quatro categorias que indicam os impactos da obesidade mórbida nas relações inter e intrapessoais do homem. Denota a juvenilização e recorrência da obesidade, a necessidade de promover ações de promoção da saúde, igualdade de direitos e superação da invisibilidade do homem obeso mórbido.
\end{abstract}

PALAVRAS-CHAVE: Obesidade mórbida. Homem. Saúde pública. Sexualidade.

\begin{abstract}
Morbid obesity experience is this study central theme which aims to trace morbidly obese men from Ceará State profile and perceptions over obese life and its nuances, supported by Metabolic Syndrome Obesity Study Brazilian Association (ABESO) and MerleauPonty Perception Phenomenology (2011). Qualitative study with phenomenological lens, developed in an obesity reference hospital of Fortaleza - Ceará, with seventeen morbidly obese men. Selection criteria was having Body Mass Index (BMI) $>30 \mathrm{~kg} / \mathrm{m}^{2}$ with comorbidities, or $>40 \mathrm{~kg}$ / $\mathrm{m}^{2}$ without comorbidities, and exclusion criteria was temporal disorientation when signing the Informed Consent Term (ICT). Data collection used as a research protocol Depth Phenomenological Interview, while data treatment and analysis were made from Merleau-Ponty Perception Phenomenology Theory perspective, respecting Resolution $466 / 2012$. Results indicate four categories that indicate morbid obesity impacts on men's inter and intrapersonal relations. Juvenilization and recurrence of obesity, necessity to foster health promotion actions, rights equality and overcoming morbidly obese man invisibility are denoted.
\end{abstract}

KEYWORDS: Morbid obesity. Man. Public health. Sexuality. 


\section{Introdução}

A obesidade tem sido apontada como um problema de saúde pública em face de sua expansão estatística para as populações mundiais. Não há um caractere específico como etnia, faixa etária ou outros que a limitem ou delimitem, antes, vem sendo reconhecida como uma patologia multifatorial e a obesidade mórbida como sendo uma sua evolução que acomete ambos os sexos, gêneros e etnias comprometendo a qualidade de vida biopsicossocial bem como a sexualidade.

A obesidade esteve presente na história da humanidade desde longas eras, nas narrativas que retratam a Era Neolítica onde a beleza das mulheres estava naquelas que tinham sua massa corporal bem acima do padrão normal, enquanto que para os homens a gordura podia ser um indicativo de status social muito embora Hipócrates tenha observado, já naquela época, que o óbito entre pessoas com elevado valor de massa corporal era mais frequente. Tal padrão foi substituído, no Império Romano, pelo padrão esbelto estando este vigente até hoje moldando a sociedade narcísica, que valoriza curvas delineadas, ainda que para atingir esse perfil prevaleça a submissão a dietas e jejuns severos.

O termo obeso é utilizado para representar a população que tem acúmulo excessivo de gorduras no corpo (Pimenta, Bertrand, Mograbi, Shinohara, \& LandeiraFernandez, 2015), ou para caracterizar uma doença metabólica resultado de aspectos multifatoriais e genéticos (Moraes, Caregnato, \& Schneider, 2014) sendo apontado como um dos fatores para a morte por Doenças Crônicas Não Transmissíveis (DCNT) em função dos outros estados de deletério de saúde a que condiciona tornando estes sujeitos, de certa forma, invisíveis a sociedade (Souza, Vilar, Andrade, Albuquerque, Cordeiro, Campos \& Ferraz, 2015; Flor, Campos, Oliveira, \& Schramm, 2015; WHO, 2006).

Longe de ser um status ou supervalorizar os corpos como na era supracitada, a obesidade se apresenta como um sério problema de saúde pública no Brasil e no mundo. A Organização Mundial de Saúde (OMS) prevê para o ano de 2025 a média de 2,3 bilhões de adultos com sobrepeso e 700 milhões de obesos, aponta ainda que os dados não serão diferentes para os Estados Unidos da América (EUA) tão menos na Europa, onde se percebe aumento da obesidade chegando a atingir seu pico, no último continente citado, por volta do início da melhor idade (WHO, 2006).

No Brasil, em 2004, segundo o Instituto Brasileiro de Geografia e Estatística (IBGE), a prevalência da obesidade estava nas regiões Sul e Sudeste com estatísticas de 12,7\% em mulheres e 8,8\% em homens (Instituto Brasileiro de Geografia e Estatística [IBGE], 2010). Já nos anos de 2008/2009 eram 37,6\% de homens com sobrepeso e $12,5 \%$ obesos enquanto as mulheres chegavam a $31,1 \%$ e $16,9 \%$, respectivamente à estatística masculina. Para o ano de 2015 a OMS previa, por estimativa, que haveria 1,9 bilhões de pessoas com sobrepeso e 600 milhões de obesos, o que confere ao Brasil a $5^{a}$ posição no ranking mundial quando o assunto é obesidade e sobrepeso (Barros, 2015; WHO, 2006).

No Ceará, de maneira geral, o DATASUS aponta um comportamento ascendente quanto aos dados de obesidade, indo de 2 casos em 2000 a 8.943 em 2007, fechando o ano de 2011 com 19.082 adultos com IMC $\geq 30$, ou seja, obeso. De acordo com a pesquisa realizada pela Vigilância de Fatores de Risco e Proteção Para Doenças Crônicas Por Inquérito Telefônico (VIGITEL) Fortaleza ocupava em 2013 a 5a posição no ranking de capitais obesas do Brasil, sendo a maioria dos obesos do sexo masculino segundo o Portal Saúde do MS (Souza et al., 2015; Brasil'1).

O aumento do Índice de Massa Corporal (IMC) torna os obesos vísiveis fisicamente, mas invisíveis quanto aos seus problemas de saúde, estigmas, preconceitos e diferentes formas de exclusão pela sua condição física comprometendo assim não somente a qualidade de vida física mais também outras dimensões do sujeito. A situação de obesidade tipo III com IMC $>35 \mathrm{~kg} / \mathrm{m}^{2}$, ou IMC $>40 \mathrm{~kg} / \mathrm{m}^{2}$ e $<50 \mathrm{~kg} / \mathrm{m}^{2}$ compromete em função das comorbidades de ordem musculoesqueléticas, genitourinário, endócrinas, cardiovasculares e/ou gastrointestinais e quando as técnicas convencionais de emagrecimento falham, recorre-se a cirurgia bariátrica como intervenção.

A obesidade mórbida traz impactos biológicos e físicos à imagem corporal devido os estados em que ficam os corpos que se estendem, consequentemente, aos aspectos emocionais e psicológicos e as

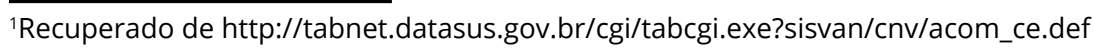


relações sociais, e ser submetido a cirurgia bariátrica pode ser a oportunidade de reinserção no mundo social em face das muitas situações de discriminação, preconceito e exclusão ocasionadas pela obesidade mórbida.

A obesidade se impõe e impõe algias e limites não apenas físicos, mas rotula, estigmatiza, promove extremo impacto no viver em sociedade quando estes têm que vivenciar o preconceito e a discriminação desprendida aos mesmos em determinados espaços, estabelecimentos e situações de vida. Em decorrência dessa realidade, a cirurgia bariátrica não é apenas por questão de saúde fisiológica, mas emocional, psicológica, de relação de bem-estar e aceitação da autoimagem. Nesta perpectiva o perceber-se obeso é ver-se fora do mundo que cultua o ser magro, esbelto em atendimento aos padrões sociais vigentes.

A obesidade é um fenômeno, logo a Fenomenologia enquanto filosofia que estuda os fenômenos reais, percebendo sua pluralidade contempla este corpus de pesquisa que parte da pergunta-problema 'Qual a percepção do homem obeso mórbido sobre sua sexualidade?', tendo como objetivo traçar o perfil do homem obeso mórbido cearense e sua percepção sobre a obesidade, utilizando os princípios da pesquisa qualitativa e seu rigor metodológico na operacionalização das tipologias de análise a partir da captação de informações com qualidade por se tartar de temas delicados como a obesidade, a sexualidade e o homem.

\section{Métodos}

Trata-se um estudo de lente fenomenológica com abordagem qualitativa a partir da experiência do homem e sua rede de relações, atribuindo 'significados' às situações vividas, desenvolvido em FortalezaCeará, em um hospital terciário da Rede de Saúde da Secretaria Estadual da Saúde (SESA), no período de agosto a dezembro de 2016.

O universo da pesquisa foram os pacientes do sexo masculino, obesos mórbidos em acompanhamento no Ambulatório de Cirurgia Bariátrica enquanto o locus fora a área de Atendimento Ambulatorial do hospital, denominada Anexo, que tem suas instalações em um espaço físico e estrutural desmembrado do prédio principal sendo este último onde são dadas as internações e procedimentos cirúrgicos de diferentes serviços prestados pela instituição de saúde.

$O$ atendimento realizado no Anexo conta com equipe multiprofissional composta por várias especialidades como endocrinologia, psicologia, cardiologia, nutrição, médico cirúrgica dentre outros enquanto as cirurgias são realizadas no prédio principal. Aquela unidade hospitalar é referência na prestação de serviços bariátricos no estado do Ceará, atendendo aos mais de 180 municípios que compõe o estado bem como a residentes de outros estados desde o ano de 2002.

Os participantes do estudo foram 17 homens selecionados a partir de critérios de elegibilidade como ter o IMC >35 associado a morbidade e/ou IMC > 40 sem comorbidades, maior de idade e participar do Programa de Cirurgia Bariátrica e de exclusão aquele(s) que por alguma razão apresentaram desorientação temporal ou espacial posterior a assinatura do Termo de Consentimento Livre e Esclarecio (TCLE).

O recrutamento dos participantes, conforme apontam Pinto \& Silva (2018), indo desde o contato à administração hospitalar e anuência da pesquisa, a imersão no campo de pesquisa, afixação de cartazes e distribuição de panfletos e informativos sobre a pesquisa com indicação do local para a coleta de dados, o recebimento do participante, ciência e assinatura do Termo de Consentimento Livre e Esclarecido (TCLE) até a coleta dos dados.

Os dados foram coletados por dois pesquisadores às sextas-feiras, no período de agosto a dezembro de 2016, na unidade hospitalar, em sala reservada, gravada, utilizando-se da lente fenomenológica com a questão disparadora "Como é a vida de um homem obeso mórbido?", técnica com maior poder de flexibilidade, deixa o participante mais a vontade permitindo os relatos próprios, antecipada por diálogo que recrutou os dados sociodemográficos a partir das variáveis faixa etária, estado civil, ocupação/profissão, procedência, religião e escolaridade e assim traçar o perfil do homem (Sampieri, Collado, \& Lucio, 2013).

A técnica do 'ponto de saturação', momento em que há repetição e não despontam novos temas (Sampieri et al., 2013) foi utilizada para definir a finalização da coleta de dados, atingida neste estudo no décimo sétimo participante, utilizando como critérios de inclusão. 
As entrevistas foram transcritas em documentos individuais, identificadas com nomes habituais escolhidos aleatoriamente em respeito ao caráter humano - Antônio, Raimundo, Paulo, Francisco, Elias, José, Pedro, Romualdo, Joaquim, Zacarias, Sebastião, Arteiro, Esmerino, João, Osvaldo, Evaristo e Eribaldo mas que não tivessem nenhuma relação com o nome oficial do participante, preservando suas identidades.

As falas dos participantes não sofreram qualquer omissão/alteração sob pena de perder informações importantes como sons, pausas e expressões faciais e/ou gestuais, metáforas, preservando, pormenorizados, os dados coletados embora não haja um processo padronizado, a exemplo do estudo quantitativo, permanecendo intacto, inclusive, o falar regionalizado ou pertencente a algum grupo social e/ou etário (Sampieri et al., 2013).

Para analisar os dados seguiu-se os passos da Análise Fenomenológica descritos por (Branco, 2014): $1^{\circ}$ acesso ao sujeito (suspensão fenomenológica); $2^{\circ}$ - aplicação do instrumento; $3^{\circ}$ - suspensão fenomenológica para levantamento das sínteses a partir das entrevistas; $4^{\circ}$ - definição das unidades de significação; e $5^{\circ}$ - formulação das categorias.

Às leituras eram feitos destaques, à lapis de cores, de excertos que dialogavam com a pesquisa que logo em seguida eram transcritos em um mural que dava visibilidade a todo o processo, depois sintetizados em unidades de sentido. No mural também se preservou o trabalho com as cores. Chegou-se a 14 unidades de sentido que foram agrupadas em 4 categorias: Sociabilidade, Sexualidade, Representação do Obeso e Medicalização.

A análise tem como referencial teórico a Fenomenologia da Percepção de Merleau-Ponty que se ocupa de visualizar o homem enquanto ser-humano multidimensional em suas vivências e a forma como as exprime através de linguagens subjetivas e/ou corporal e por todos os movimentos que o homem faz quanto aos contextos sociais, individuais. Tais experiências preconizam ser o corpo um objeto, mas não este distante do eu, antes pode ser meio de diálogo e de comunicação (Merleau-Ponty, 2011).

O estudo teve parecer do Comitê de Ética e Pesquisa da Universidade de Fortaleza (CEP-UNIFOR) sob $\mathrm{N}^{\circ}$ 1.666.792 (CAAE 56819716.8.0000.5052) de 08/08/ 2016 assim como do Comitê de Ética e Pesquisa do Hospital Geral Dr. César Cals, instituição co-participante da pesquisa, com No 1.714 .797 de 06/09/2016 (CAAE 56819716.8.3001.5041).

\section{Resultados e discussão}

\section{O perfil sociodemográfico}

Participaram da pesquisa 17 homens suas características socidemograficas estão representadas na tabela 1.

Tabela 1. Perfil sociodemográfico $(n=17)$ (continua)

\begin{tabular}{|c|c|c|c|}
\hline VARIÁVEIS & SUBDIVISÕES & QTD & $\%$ \\
\hline \multirow[t]{3}{*}{ Faixa etária } & 20 a 40 anos & 14 & 82 \\
\hline & 41 a 60 & 2 & 14,5 \\
\hline & Não referiu & 1 & 3,5 \\
\hline \multirow[t]{3}{*}{ Etnia } & Branco & 6 & 35 \\
\hline & Moreno & 4 & 25 \\
\hline & Negro & 1 & 5 \\
\hline \multirow[t]{3}{*}{ Estado Civil } & Solteiro & 8 & 47 \\
\hline & Casado & 5 & 29 \\
\hline & União Estável & 4 & 24 \\
\hline \multirow[t]{4}{*}{ Ocupação/Profissão } & Autônomo & 3 & 18 \\
\hline & Desempregados & 3 & 18 \\
\hline & Cozinheiros & 2 & 12 \\
\hline & Outras & 9 & 53 \\
\hline
\end{tabular}


Tabela 1. Perfil sociodemográfico ( $n=17)$ (conclusão)

\begin{tabular}{|c|c|c|c|}
\hline VARIÁVEIS & SUBDIVISÕES & QTD & $\%$ \\
\hline \multirow[t]{3}{*}{ Procedência } & Capital & 11 & 65 \\
\hline & Interior & 4 & 24 \\
\hline & Outros Estados & 2 & 12 \\
\hline \multirow[t]{3}{*}{ Religião } & Católicos & 9 & 53 \\
\hline & Evangélicos & 6 & 35 \\
\hline & Não referiram & 2 & 12 \\
\hline \multirow[t]{7}{*}{ Escolaridade } & Ens. Fund. Incompleto & 4 & 24 \\
\hline & Ens. Fund. & 2 & 12 \\
\hline & Ens. Medio. Incompleto & 4 & 24 \\
\hline & Ens. Médio & 1 & 6 \\
\hline & Ens. Sup. Incompleto & 2 & 12 \\
\hline & Ens. Superior & 3 & 18 \\
\hline & Não referiu & 1 & 6 \\
\hline \multirow[t]{3}{*}{ Peso de Ingresso } & 120 a $180 \mathrm{~kg}$ & 10 & 59 \\
\hline & 181 a $240 \mathrm{~kg}$ & 5 & 29 \\
\hline & Não referiu & 2 & 12 \\
\hline \multirow[t]{3}{*}{ Peso Atual } & 110 a $180 \mathrm{~kg}$ & 14 & 82 \\
\hline & 181 a 240 & 2 & 12 \\
\hline & Não referiu & 1 & 6 \\
\hline \multirow[t]{18}{*}{ Comorbidades } & Hipertensão Arterial & 8 & 20 \\
\hline & Dor Osteomioarticular & 7 & 17 \\
\hline & Diabetes & 5 & 12 \\
\hline & Dificuldade Motora & 3 & 7 \\
\hline & Depressão & 2 & 5 \\
\hline & Colesterol & 2 & 5 \\
\hline & Desconforto Respiratório & 2 & 5 \\
\hline & Ansiedade & 1 & 2 \\
\hline & Hérnia de Púbis & 1 & 2 \\
\hline & Pedra na Vesícula & 1 & 2 \\
\hline & Miocardiopatia & 1 & 2 \\
\hline & Ácido Úrico & 1 & 2 \\
\hline & Tireoidismo & 1 & 2 \\
\hline & Insuficiência Respiratória & 1 & 2 \\
\hline & Cardiomegalia & 1 & 2 \\
\hline & Erisipela & 1 & 2 \\
\hline & Acantose Nigrican & 1 & 2 \\
\hline & Nenhuma & 2 & 5 \\
\hline
\end{tabular}

Fonte: Dados da Pesquisa (2016).

Os dados sociodemográficos revelam o perfil do homem obeso mórbido atendido no HGCC localizado em Fortaleza-Ceará. É importante destacar que todos os 17 participantes atenderam aos critérios mínimos preconizados nos preceitos éticos deste estudo sendo, inclusive, premissa para aceitação no programa que os mesmos já estejam no grau III da obesidade que se relaciona ao IMC em torno de 35 a $40 \mathrm{~kg} / \mathrm{m}^{2} \mathrm{com}$ comorbidades; $>40 \mathrm{~kg} / \mathrm{m}^{2}$ ou ainda IMC de 30 a $35 \mathrm{~kg} / \mathrm{m}^{2}$ quando reconhecido pelo profissional médico que a comorbidade é grave segundo a especialidade daquela, não podendo ser omisso o fator de inviabilidade de tratamento clínico da comorbidade e quanto a idade que sejam maiores de 18 anos e menores de 65 para o direito livre de opinar o aceite, ou não, sem que haja decisões de terceiros (SBCBM, 2013). 
De fato não foi observado nas dependências da unidade de atendimento e seguimento do Programa de Cirurgia Bariátrica do HGCC nenhuma criança e/ ou adolescente por não se tratar aquele ambulatório de segmento pediátrico reforçado pela inconclusão científica de benefícios da cirurgia até os 16 anos ainda que os estudos indiquem que a obesidade nestas duas fases da vida humana estão relacionadas ao desenvolvimento e avanço das tecnologias contrapondo estudos realizados em 2003 que apontavam que nestas duas fases a obesidade havia estagnado (SBCBM, 2013).

A média de idade dos participantes é de 31,8 com desvio padrão de 25 a 30 anos, concorrendo com os resultados encontrados em outros estudos que apontam a média de idade de 40,9 anos, 35 a 44 anos, 37,8 anos e de 42,7 anos (Schere, 2015). Neste estudo há predomínio na faixa etária de 20 a 40 anos, o que apenas aproxima da faixa etária de 30 a 49 anos, um pouco mais distante de 46 a 55 anos atingindo principalmente a parcela da população em idade fértil biologicamente, ativa e apta quanto ao mercado de trabalho (Rodrigues \& Silveira, 2015; Flor et al, 2015). Outra característica do perfil sociodemográfico que merece destaque neste primeiro momento é o nível de escolaridade. Neste estudo 06 (seis) participantes afirmam ter o Ensino Fundamental, sendo 04 (quatro) deles incompleto e 02 (dois) completo. O Ensino Fundamental é a primeira etapa da Educação Básica que antes era cursada em 08 (oito) anos e desde o ano de 2006 passou a vigorar em 09 (nove) anos dividido para fins didáticos em Ensino Fundamental Anos Iniciais e Ensino Fundamental Anos Finais precedida da Educação Infantil conforme preconize o Ministério da Educação do Brasil.

Por se tratar de um ensino sequencial não se consegue chegar ao Ensino Médio, último estágio da Educação Básica, sem antes cursar as etapas citadas anteriormente e assim galgar o Ensino Superior. É a premissa da aquisição de novos níveis de escolaridade, da construção de novos conhecimentos e a possibilidade de deliberar sobre suas decisões, tendo ciência do que é correto ou não, que planifica a ideia da necessidade de estudar uma vez que o estudo e a obesidade ou não obesidade estão diretamente relacionados.

Aponta-se que o maior aumento de peso tem se relacionado significativamente negativo ao menor nível de escolaridade sendo mais acentuado em homens que em mulheres concorrendo com os dados encontrados neste estudo quando a maior parcela desse estudo está assentada nos homens obesos mórbidos que não concluíram a Educação Básica. Estudos realizados com mulheres de comunidades do Estado do Rio de Janeiro como Rocinha, Campos Elíseos-Duque de Caxias e Olaria ratificam que quanto maior o nível de escolaridade menores são as possibilidades de obesidade. Em João Pessoa, Paraíba, detectou-se que o nível de escolaridade dos pais tem influência direta no sobrepeso e obesidade de seus filhos, tendo significância positiva mais para moças que rapazessemelhante ao encontro no estudo realizado em Goiás. (Rodrigues \& Silveira, 2015)

Pinto e Silva (2018) ratificam que estudos multicêntricos como o relatório da WHO Monitoring Trendsand Determinants in Cardiovascular Disease Project (MONICA) desenvolvido em 29 países ou as bases de dados do IBGE, identificam que a mulher é mais influenciada à obesidade que os homens, dependendo de seu nível de escolaridade, entretanto há outros estudos que indicam não haver relação de significância negativa entre homens e escolaridade.

É importante destacar que o cenário contemporâneo e o estímulo ao consumo exacerbado têm importantes parcelas contributivas ao processo de ganho excessivo de peso além de estimular o sedentarismo. A situação da obesidade e sua multifatorialidade não desmistifica o fato de que a população da zona urbana tem maior prevalência haja vista sua maior possibilidade de acesso aos produtos industrializados. É esse sistema social, as mudanças culturais, associadas a franca evolução dos recursos tecnológicos que provocam a mudança nos hábitos alimentares ao passo que facilitam ações e atividades diárias que acabam por acomodar o corpo e reduzir as atividades físicas.

Impossível não citar a explosão comercial dos fast-foods e dos alimentos industrializados que em poucos minutos dão o prato pronto, mas que são potencialmente prejudiciais ao corpo em razão de todos os componentes aditivos para conservação. O investimento do marketing na divulgação dos alimentos direcionados a crianças e adultos tem conseguido atingir um número cada vez maior da população, ou seja, se oferece cada vez mais comida industrializada e se segue menos ainda as preconizações da OMS e do MS. 
Entre os 17 participantes variadas profissões são ou foram exercidas, como mostra a tabela anterior e cada uma experimenta, ou não, problemas relacionados ao trabalho. A partir dos dados d quadro 1 surge outro tópico de relevância à vida do homem obeso mórbido que é a questão profissional que já no estudo de Griep et al., (2014) indica haver relações entre o trabalho à noite e o processo de ganho de peso.

Além das questões conceituais e etiológicas, a obesidade reformula constantemente seu escopo fisiopatológico se relacionando, também, as situações trabalhistas, seja pela sua existência, seja pelos impactos que causam na procura por um emprego, ou nos impactos na execução destes. O aumento de peso até atingir a morbidade tem, também, o poder de interferir na vida profissional dos participantes deste estudo. Ser obeso limita o acesso ao mercado de trabalho por diversos fatores. Ao tentar inserção no mercado de trabalho, o homem obeso mórbido sofre, de novo, com o preconceito institucional.

O estudo de Beltrão e Pena (2013), realizado a partir de bases de dados esclarece que há profissões no mercado de trabalho que sofrem influência direta da morbidade e da Síndrome Metabólica como trabalho noturno, excesso de trabalho dentre outros. As dificuldades relatadas também se relacionam as limitações físicas e também foram narradas como impedimentos a continuidade no trabalho e no programa, pois alguns dos homens obesos mórbidos têm, em razão destas limitudes, suas atividades reduzidas.

A relação entre consumismo industrializado e produção da obesidade já é relatado no estudo de que trata da obesidade infantil assim como o estudo de que aponta a evolução da televisão como fator de risco à patologia em infantes. Em se tratando de obesidade adulta identificou-se, em estudo com nipo-brasileiros que a obesidade em homens está relacionada ao consumo de alimentos embutidos (Cristofoletti, Gimeno, Ferreira e Cardoso, 2013).

O relato de dificuldades relacionadas ao trabalho não foi comum a todos os participantes do estudo, parecendo não ser uma situação real, entretanto o fato de atribuir a normalidade a uma situação que é considerada por outros que vivenciam o mesmo estado como anormal é reconhecido por Merleau-Ponty (2011) como um recurso utilizado para sobrepor a ausência do corpo. É uma forma de recorrer todo o contorno do objeto para tentar enganar ao outro quando na verdade engana-se a si mesmo. Até existe a tentativa do estímulo pelo corpo, rebuscando a existência.

Estudo realizado em Bauru, São Paulo, indica que a obesidade abdominal é a que concorre com maiores riscos de comorbidades aos que são acometidos pela morbidade (Turi, Codogno, Fernandes, \& Monteiro, 2014), pois promove a intolerância à prática de exercícios físicos e em decorrência as adipocinas - proteínas que funcionam como sinalizadores e que tem sua excreção pelo tecido adipose - tem considerável crescimento, consequentemente há uma limitação a absorção da insulina nas regiões periféricas. A causa destas disfunções está na falha no receptor ou diminuição da sensibilidade do organismo do obeso mórbido aos efeitos da leptina, um hormônio peptídico.

Os participantes revelam suas capacidades de perceber-se enquanto corpo que ocupa um maior espaço físico, que tem limitações quanto a sua motricidade, todavia associam a dor como o fio condutor à percepção de que os sistemas e órgãos se correlacionam e só então percebem que estes não podem ser vistos apenas como uma sequência distinta de pontos e/ou estruturas que não se envolvem, apenas alinhadas paralelamente sem nenhuma relação, sem nenhuma intersecção e, mesmo com o autoconhecimento associam ainda o modelo cartesiano de ver o homem, com olhar direcionado apenas ao estado da dor (Merleau-Ponty, 2011).

O estar obeso mórbido traz outros agravantes que estrapolam sua questão anatomofisiológica e atinge outros ambientes como o escolar e profissional onde o viver obeso traz impactos psicoemocionais e sociais, sendo ainda mais devastadores quando a criança é a vítima desse preconceito em função de sua massa corpórea. Essa situação preconceituosa, o já afamado Bullying, tem forte reflexo dentro do espaço da escola, local que tem como missão social desenvolver a cidadania em seus educandos, primando pelos valores da igualdade entre pares. A ocorrência deste tipo de violência no espaço escolar e sua ascensão não se configuram como foco deste estudo (Macedo, 2015).

Se o comportamento segundo Nightingale depende do ambiente, e para Vygotsky depende das interações sociais, culturais e históricas e o ambiente é o resultado dos elementos que formam os conjuntos, os grupos, depreende-se que os resultados das 
experiências vividas são determinantes para o comportamento introvertido, reverberendo na ingerência do reconhecimento das violências simbólicas e institucionais que vivencia na escola a partir do Bullying.

O estudo de Malta, Andrade, Claro, Bernal e Monteiro (2014) indica que nos Estados Unidos há prevalência de pelo menos $20 \%$ de um total de pouco mais de 15.500 estudantes que sofreram Bullying e que no Brasil em 2010 com estudo feito com pouco mais de 5.000 alunos esse valor chegou a $12 \%$.

O cerne da discussão sobre os problemas que são vividos e vivenciados pelos obesos são vários e diversos. Não obstante a todas as questões já apontadas tem-se como questão de ordem primária o problema das comorbidades associadas à obesidade, decorrentes e/ou incidentes e prevalentes como são apresentadas neste estudo.

Os quadros patológicos são os mais diversos e todos têm grau de severidade máxima, pois são potencias assassinos de homens obesos mórbidos. É óbvio que nem todos passam pelas mesmas comorbidades e mesmo aqueles que as vivenciam não conferem o mesmo grau. A experiência de outras doenças e associação destas à obesidade é que tornam difícil defini-la e a torna um dos mais graves problemas de saúde pública da contemporaneidade, todavia e não obstante a todos os riscos já apontados socialmente até aqui, afeta nas relações sociais e profissionais nos mais diferentes espaços (Abeso, 2016).

A obesidade mórbida por si só, como já apontado neste estudo, foi classificada pela OMS como uma Doença Crônica Não Transmissível (DCNT) desde o ano de 2007, sendo reconhecida como uma patologia multifatorial com fisiopatologia relacionada a hormônios que promovem a sensação de saciedade, a leptina (Abeso, 2016).

As comorbidades mais recorrentes que promovem limitação física, redução da mobilidade e o crescimento do número de óbitos, relatadas também em vários estudos são a Hipertensão Arterial Sistêmica (HAS) e Diabetes Mellitus (DM) (Griep et al., 2014) sendo esta uma parcela ínfima de autores que apontam tais comorbidades, visto que há uma extensa literatura que aponta a HAS e o DM como as principais comorbidades sem, todavia, restringir apenas a estas.

Há na literatura, semelhantes achados que este estudo pode se equiparar como tireopatias, doenças cardiovasculares e osteoartrites, apneia do sono e cânceres de cólon. Outros achados dão conta de perdas de dentes, doenças no hipotálamo e alterações metabólicas sendo estas não relatadas pelos participantes deste estudo e que também não são as únicas (Pilotto, 2014).

Segundo a Associação Brasileira para o Estudo da Obesidade e Síndrome Metabólica (ABESO) há uma série de outras comorbidades que favorecem ao estado patológico do obeso mórbido como doenças cerebrovasculares, colelitiasis, compatível com este estudo, hipercolesterolemia, dislipidemia, redução do High Density Lipoproteins (HDL), intolerância a glicose, hiperinsulinemia, transtornos menstruais. Por outro lado, os problemas de ordem psicológica são relatados nestes estudos, mas não tiveram expressão no estudo realizado com mulheres no pós-Cirurgia Bariátrica.

Como resultados às comorbidades estão as questões de mobilidade que são reduzidas e seus impactos na vida dos homens obesos mórbidos se destacando, expressivamente nas narrativas, as complicações com o uso do transporte público que são recordistas quando se trata de excluir e promover o preconceito e a discriminação com o homem obeso mórbido. A inacessibilidade ao transporte público é, também, um dos complicadores da qualidade de vida haja vistas a necessidade de mobilidade do passageiro, inclusive para solucionar problemas de ordem pessoal e de saúde.

\section{As unidades e categorias}

A partir das entrevistas e seguindo os cinco passos da análise fenomenológica, foram identificadas 14 unidades de sentido que foram organizadas em 4 categorias. 
Quadro 1. Percepções do homem obeso mórbido e categorias

\begin{tabular}{|c|c|c|}
\hline $\begin{array}{l}\text { PERCEPÇÕES/UNIDADES DE } \\
\text { SENTIDO }\end{array}$ & & CATEGORIAS \\
\hline $\begin{array}{l}\text { Limitações físicas na obesidade } \\
\text { mórbida }\end{array}$ & $\begin{array}{l}\text { [...] dificuldades em coisas simples, tipo cruzar as } \\
\text { pernas, amarrar um sapato, calçar meia que eu não } \\
\text { consigo calçar, virar a perna para trás }\end{array}$ & \multirow{7}{*}{ Sociabilidade } \\
\hline Relações na obesidade mórbida & $\begin{array}{l}\text { [...] eu deambulava } 5 \text { minutos, já cansava, entende?!, } \\
\text { cansava, na parte sexual também da gente. }\end{array}$ & \\
\hline $\begin{array}{l}\text { Preconceito na obesidade } \\
\text { mórbida }\end{array}$ & $\begin{array}{l}\text { Fora as criancinhas que passa que fala [...] 'olha aí } \\
\text { como ele é gordo', fico super triste com isso, sabe?! } \\
\text { [...] mas nunca sofri preconceito no trabalho, nem } \\
\text { social. }\end{array}$ & \\
\hline Trabalho e obesidade & [...] bomba relógio que a qualquer & \\
\hline Mórbida & $\begin{array}{l}\text { momento vai enfartar e vai trazer um ônus nocivo } \\
\text { para a empresa. }\end{array}$ & \\
\hline $\begin{array}{l}\text { Transporte público e obesidade } \\
\text { mórbida }\end{array}$ & $\begin{array}{l}\text { [...] muitas vezes o motorista não abre a porta da } \\
\text { frente, lhe dando o direito de subir pela frente por } \\
\text { conta de você conseguir poder passar na catraca [...] }\end{array}$ & \\
\hline Direitos Humanos e obesidade & $\begin{array}{l}\text { [...], o obeso tem a preferência e essa preferência não } \\
\text { é dada. }\end{array}$ & \\
\hline $\begin{array}{l}\text { Sexualidade na obesidade } \\
\text { mórbida }\end{array}$ & $\begin{array}{l}\text { [...] tem posições que dá pra fazer né, não são todas as } \\
\text { posições, [...], o peso interfere, [...], mas na relação em } \\
\text { si [...]. }\end{array}$ & \multirow[b]{2}{*}{ Sexualidade } \\
\hline Gênero na obesidade mórbida & $\begin{array}{l}\text { [...], é muito complicado a vivência da sexualidade } \\
\text { sendo obeso, é complicado porque é algo que lhe } \\
\text { deixa constrangido, [...]. }\end{array}$ & \\
\hline $\begin{array}{l}\text { Corpo e imagem na obesidade } \\
\text { mórbida }\end{array}$ & $\begin{array}{l}\text { [...] a sociedade em si, ela estipula um estereótipo } \\
\text { físico, [...], pessoas que não se encaixem naquele } \\
\text { padrão, elas sejam exclusas [...]. }\end{array}$ & \multirow{2}{*}{$\begin{array}{l}\text { Representaçao } \\
\text { do obeso }\end{array}$} \\
\hline Bullying na obesidade mórbida & $\begin{array}{l}\text { [...] eu não me recordo de ter sofrido preconceito, } \\
\text { assim, brincadeira, mas não Bullying né? }\end{array}$ & \\
\hline $\begin{array}{l}\text { Desencadeador da obesidade } \\
\text { mórbida }\end{array}$ & $\begin{array}{l}\text { Sou obeso acho que desde os quinze para dezesseis } \\
\text { anos, [...], minha mãe e meu pai são separados. }\end{array}$ & \multirow{4}{*}{ Vida social } \\
\hline $\begin{array}{l}\text { Cirurgia bariátrica na obesidade } \\
\text { mórbida }\end{array}$ & Eu já to fazendo por conta da saúde, hipertensão, [...]. & \\
\hline $\begin{array}{l}\text { Comorbidades na obesidade } \\
\text { mórbida }\end{array}$ & $\begin{array}{l}\text { Meus membros inferiores não suportam, minhas veias } \\
\text { doem, meu corpo é uma constância de dor. }\end{array}$ & \\
\hline $\begin{array}{l}\text { Implicações da cirúrgia } \\
\text { bariátrica }\end{array}$ & $\begin{array}{l}\text { Espero uma mudança de vida } 100 \% \text { pra melhor, não } \\
\text { pra estética, mas pra minha saúde, [...]. }\end{array}$ & \\
\hline
\end{tabular}

Fonte: Dados da Pesquisa (2016).

Enquanto estudo qualitativo buscou-se a partir dos relatos, inferir as percepções que os participantes têm quanto à obesidade e os universos envolvidos identificando quatro categorias.

\section{Categoria 1 - Sociabilidade}

Esta envolve os sentidos que o homem obeso mórbido atribui a sua vida social. Surge com o repatriamento às próprias vidas, promove a reflexão de sua vida social em todos os contextos desde as suas limitações físicas às atividades diárias e o desrespeito aos seus direitos, a partir da pergunta disparadora.

A categoria revela a limitação dos homens a partir de respostas monossilábicas evitando exposição de suas percepções e concepções acerca do próprio corpo e se o faz é em dois polos opostos, o do medo, do receio, do temor ou no sentido oposto o do fascínio, o do galanteamento, o da exposição com propósitos de conquistar, o que acabou requerendo que houvesse todo um diálogo anterior. 
Essa parece ser uma característica atemporal do homem, o temor ou receio, ou ainda a pouca habilidade de se abrir para outra pessoa. Essa característica faz parte de todo um patriarcado que confere ao homem a alcunha de macho, a virilidade e a ideia de que seus problemas são inexistentes, não precisam e nem devem ser discutidos com terceiros, salvo quando são agravos ou conferem riscos a sua condição de saúde e de vida, denotando inclusive a pouca atenção/ percepção/cuidado com sua própria saúde e mais ainda como essas questões implicam na sua saúde e vida social, nos fenômenos da existência do homem (Merleau-Ponty, 2011).

O exposto reforça então a dificuldade que o homem tem de se expor, de expor seus problemas e suas individualidades, pois no ideário masculino o dito homem, cabra macho, não tem problemas, não precisa estar em busca de serviços de saúde salvo por uma situação extrema.

Esta categoria tem sua exposição a partir do que os homens relatavam de dificuldades no desenvolvimento de suas Atividades da Vida Diária (AVD) assim como das condições de vivência e de uso dos recursos públicos sejam eles os transportes, sejam eles os espaços dos estabelecimentos comerciais.

\section{Categoria 2 - Sexualidade}

Esta categoria faz menção à sexualidade do homem obeso mórbido, as dificuldades vividas dando possibilidades de análise sobre os impactos causados à vida cotidiana pelo IMC acima do padrão considerado normal de saúde, não pensando no culto ao corpo escultural, mas a qualidade de vida.

Esta categoria busca apontar as principais dificuldades identificadas nas narrativas dos homens obesos mórbidos quanto a realidade de sua sexualidade, buscando analisar/compreender todas as situações vivenciadas por aqueles e os impactos causados na vida cotidiana visto que quem tem o IMC acima dos padrões normais apontados pela ABESO bem como pela WHO, não se adequa as normas padronizadas da sociedade e conjectura-se que a vivência do sexo, do ato sexual e da sexualidade são gargalos na luta pela vida se não plena, mas no mínimo satisfatória.

A realidade é bem mais truncada do que simplesmente aquilo que o senso comum costuma preconizar, indo para além do que aponta a literatura sobre o assunto, desvelando a realidade experimentada por cada um dos participantes deste estudo e, a partir de suas vivências, os mecanismos desenvolvidos na busca pela superação, longe do que fica ratificado no ideário social comum que legitima as dificuldades vividas por um homem obeso mórbido quanto a sua sexualidade.

A imagem que se tem do homem é carregada em duas possibilidades, sob a égide do homem como o 'sexo forte': a primeira delas, retrógrada, quanto aos processos discursivos de gênero e de identidade, atribui a virilidade como a possibilidade de ser efetivamente homem, reforçado pela ideia de força física, de potência e de domínio da situação e insaciável é a utilização de forma deturpada dos significados de homem e de macho, associando exclusivamente ao biologicismo. Esta forma de atrelar as ações masculinas a alguma situação, denotando sua força pode ter conotação do membro fantasma, onde mesmo sabendo da inexistência ou incapacidade o organism continua agindo como se estivesse em sua totalidade (Merleau-Ponty, 2011).

A segunda, em contraposição à primeira trabalha com o homem contemporâneo, preocupado consigo, com o corpo, com a saúde, muito mais introjetado pela cultura midiática que pelo processo de preocupação pessoal com sua própria saúde. É incontestável que as relações de gênero e a vivência da sexualidade tem sido desde outrora um assunto difícil de discutir, considerado e nominado tabu e esse grau de dificuldade eleva-se ainda mais quando se trata de discutir a sexualidade masculina. Não é de todo difícil questionar o que fez este gênero manter-se incólume a propostas de pesquisa por muito tempo e talvez ainda não se tenha a resposta precisa para isso.

O olhar projetado sobre o homem em se tratando de sua sexualidade tem perdurado em vertentes mecânicas e cartesianas, mantém a ideia do homem dominador e superior na vivência da sexualidade, mesmo o surgimento de outras variâncias como a metrossexualidade que aponta abertura masculina para um novo escopo de homem, mais acessível e articulado, seguidor do padrão midiático de homem ideal e viril, sem problemas com sua sexualidade.

\section{Categoria 3 - Representação do Obeso}

O homem teve ao largo de sua história se desprovido da preocupação com a imagem corporal, com a 
forma física do corpo e até cultivou, por muitos anos, o corpo gordo, o corpo que excedia os limites de massa corpórea, uma vez que este indicava até alto padrão econômico que colocava acima dos demais aqueles que eram gordos. A prova desse fato é cabal nas estátuas e estatuetas da Era Antiga e Medieval quando os corpos não tinham formas e nem curvas delineadas e traçadas.

É nesta dificuldade de convivência consigo, com seu corpo e com a sexualidade por parte do homem obeso mórbido que emergiu esta categoria que buscou reunir as reflexões sobre o reconhecimento do homem obeso quanto ao próprio corpo e quanto a percepção do corpo do outro e como ele converge todas essas percepções para sua autocrítica de forma muito peculiar quando trata de como a mídia tem tratado esse culto a forma e ao corpo, mantido a ideia de que a boa forma física é mais que uma necessidade de saúde, é condição para a aceitação social.

Retrata o contradito no processo de evolução do ser humano quando outrora a obesidade representava um status em oposição ao estado de magreza hoje. Tal conflito gera o homem obeso insatisfeito com sua autoimagem.

As narrativas dos participantes deste estudo não destoaram do exposto anteriormente. Ainda que a literatura aponte que há limitações físicas, que as AVDs ficam prejudicadas, que há impactos no peso corpóreo houve uma intensa preocupação em reproduzir o discurso de que tudo está bom, de que tudo está dentro do esperado.

Para além dessa noção de dizer que as coisas estão bem e são normais na vida do homem obeso mórbido está a realidade dos impactos promovidos no campo das relações conjugais e como estas influenciam na vida destes homens. Durante as narrativas por mais que dissessem que estava tudo dentro das normalidades era possível perceber nos gestos e nos movimentos que havia corpos espinhosos a serem manipulados de forma muito sensível e delicada pelos homens.

O medo de perder a esposa, o medo da não aceitação do corpo pelo(a) cônjuge é uma marca registrada e de certa forma obriga-os a experimentar sentimentos como a possibilidade de traição, o medo quanto a impotência sexual, a preocupação com a disfunção erétil e principalmente o receio de não atender as expectativas de quem está vivenciando a relação naquele momento.

Os estados afetivos são problemas identificados, porém menos tocados e discutidos, é uma dificuldade e acaba por despertar situações de alegria e de dor, de prazer e de medo. Quando não acontece a identidade desses dois sentimentos, dessas duas realidades surge, ou se sugere uma nova forma de representação. Um dos participantes do estudo ratificou tal dificuldade e confirma a dificuldade do doente, e é assim que o homem obeso mórbido se percebe, confluindo com a fala de que "Um doente nunca procura por si mesmo, o ato sexual" (Merleau-Ponty, 2011:214).

\section{Categoria 4 - Medicalização}

Esta categoria emerge a partir de elementos que envolvem perspectivas, medos e desafios presentes nas narrativas dos homens obesos mórbidos. São questões que se relacionam as dificuldades vividas quanto as limitações físicas, a não aceitação de seus corpos, o processo de autocrítica a autoimagem, o frequente medo da morte, os impactos do preconceito e da discriminação no espaço social, cultural, familiar e até mesmo pessoal, a dificuldade de vivenciar a plenitude de sua sexualidade e como esta não vivência impacta nos relacionamentos familiares são motivações para que o homem obeso mórbido procure a Cirurgia Bariátrica como uma das formas de resolução de seus problemas.

O impacto da obesidade não se restringe especificamente a mobilidade dentro e fora dos contextos sociais, no uso e vivência do processo discriminatório dentro dos coletivos, mas também tem relações diretas com a vida íntima do homem obeso mórbido. Pontue-se aqui que essa vivência da intimidade não está relacionada especificamente as dificuldades de posição para a realização do ato sexual, como já apontado anteriormente, mas também é relacionada a higiene íntima

Um homem com problemas sociais, com enfrentamento de preconceito por sua condição física, que não consegue vivenciar sua sexualidade e tem conflitos com o próprio corpo é candidato apto a experimentar o que aponta a Categoria Medicalização que emergiu a partir de elementos que envolvem perspectivas, medos e desafios presentes nas entrevistas dos homens obesos mórbidos, que motivam à 
Cirurgia Bariátrica como uma das formas de resolução de seus problemas.

É importante que se reitere que não são as comorbidades as únicas e exclusivas responsáveis pela procura pela cirurgia bariátrica, mas também pela busca estética, por isso em adolescentes até 16 anos ela não tem quaisquer indicações, ficando a clínica responsável em contrapor o atual quadro patológico da obesidade (Abeso, 2016).

\section{Conclusões}

Na presente pesquisa a maior proporção foi de homens obesos mórbidos adultos jovens em processo para a cirurgia bariátrica, com dificuldades na realização das atividades cotidianas mais básicas assim como nas interações sociais conjugáveis ou dos grupos sociais, não sendo diferentes os impactos dessa condição de saúde na autoimagem e nas comorbidades decorrentes ao ser obeso mórbido. Os limites do estudo referem-se a pouca evidência científica sobre obesidade mórbida, sexualidade e homem, a resistência e não adesão à pesquisa pelos participantes principalmente quando era esclarecido, pessoalmente sobre o que se iria trata.

A metodologia qualitativa se apresentou de fundamental importância para atingir o objetivo da pesquisa e de sua pergunta problema. De forma complementar, o rigor metodológico que a pesquisa qualitativa implica e a forma como os conteúdos foram tratados e analisados possibilita compreender outras nuances do ser homem obeso mórbido no Século XXI.

Esta pesquisa contribue de forma significativa para subsidiar nacional e internacionalmente outros estudos que envolvam a obesidade mórbida em homens e sua sexualidade tendo como aporte metodológico a metodologia qualitativa.

\section{Agradecimentos}

À Universidade de Fortaleza e o PPG em Saúde Coletiva, a Direção-Geral do HG César Cals (Fortaleza-CE) através do Centro de Estudos Aperfeiçoamento e Pesquisa pelo apoio manifestado e disponibilidade em auxiliar em todas as demandas que eram inerentes ao estudo. Este artigo é resultado de pesquisa aprovada para apresentação no $7^{\circ}$ Congresso Ibero-Americano em Investigação Qualitativa - CIAIQ, realizado de 10 a 13 de julho de 2018 em Fortaleza, Ceará, Brasil.

\section{Contribuições dos autores}

Pinto, F. R. M. participou da concepção, delineamento, coleta de dados, análise dos dados, interpretação dos resultados, redação do artigo, revisão final do texto, encaminhamento do artigo. Silva, C. A. B. participou da concepção, delineamento e revisão final do texto.

\section{Conflitos de interesses}

Nenhum conflito financeiro, legal ou político envolvendo terceiros (governo, empresas e fundações privadas, etc.) foi declarado para nenhum aspecto do trabalho submetido (incluindo mas não limitando-se a subvenções e financiamentos, participação em conselho consultivo, desenho de estudo, preparação de manuscrito, análise estatística, etc.).

\section{Referências}

Associação Brasileira para o Estudo da Obesidade e da Síndrome Metabólica (2010). Atualização das diretrizes para o tratamento farmacológico da obesidade e do sobrepeso: posicionamento oficial da ABESO/SBEM - 2010. Abeso, 47, 4-18. Recuperado de http://www.abeso.org.br/pdf/ diretrizes2010.pdf

Barros, F. (2015). Qual o maior problema de saúde pública: a obesidade mórbida ou a cirurgia bariátrica no Sistema Único de Saúde? Revista do Colégio Brasileiro de Cirurgiões, 42(2), 136-137. Recuperado de http://www.scielo.br/pdf/ rcbc/v42n3/pt_0100-6991-rcbc-42-03-00136.pdf. doi: 10.1590/0100-69912015003001

Beltrão, F. L. L., \& Pena, P. G. L. (2013). Associação entre Síndrome Metabólica e Saúde no Trabalho. Revista Brasileira de Medicina do Trabalho, 11(1), 3-18. Recuperado de http:// www.rbmt.org.br/details/61/pt-BR/associacao-entresindrome-metabolica-e-saude-no-trabalho

Branco, P. C. C. (2014). Diálogo entre análise de conteúdo e método fenomenológico empírico: Percursos históricos e metodológicos. Revista Da Abordagem Gestaltica, 20(2), 189-197. Recuperado de http://pepsic.bvsalud.org/pdf/ rag/v20n2/v20n2a06.pdf

Brasil. Ministério da Saúde. DATASUS - Departamento de Informática do SUS. Recuperado de http://tabnet.datasus. gov.br/cgi/tabcgi.exe?sisvan/cnv/acom_ce.def 
Cristofoletti, M. F., Gimeno, S. G. A., Ferreira, S. R. G., Cardoso, M. A., \& Japanese-Brazilian Diabetes Study Group. (2013). Associação entre consumo de alimentos embutidos e obesidade em um estudo de base populacional nipobrasileiros. Arquivos Brasileiros de Endocrinologia \& Metabologia, 57(6), 464-472. Recuperado de http://www. scielo.br/pdf/abem/v57n6/09.pdf. doi: 10.1590/S000427302013000600009

Flor, L. S., Campos, M. R., Oliveira, A. F., \& Schramm, J. M. A. (2015). Diabetes burden in Brazil: fraction attributable to overweight, obesity, and excess weight. Revista de Saúde Pública, 49(29). Recuperado de http://www.scielo.br/pdf/ rsp/v49/0034-8910-rsp-S0034-89102015049005571.pdf. doi: 10.1590/S0034-8910.2015049005571

Griep, R. H., Bastos, L. S., Fonseca, M. J. M., Silva-Costa, A., Portela, L. F., Toiavanen, S., \& Rotemberg, L. (2014). Years worked at night and body mass index among registered nurses from eighteen public hospital in Rio de Janeiro, Brazil. BMC Health Services Research, 14(603). Recuperado de https://www.ncbi.nlm.nih.gov/pmc/articles/PMC4264337/ pdf/12913_2014_Article_603.pdf. doi: 10.1186/s12913-0140603-4

Instituto Brasileiro de Geografia e Estatística. (2010). Pesquisa de Orçamentos Familiares 2008-2009: antropometria e estado nutricional de criança, adolescentes e adultos no Brasil. Rio de Janeiro: IBGE. Recuperado de https://biblioteca.ibge. gov.br/visualizacao/livros/liv45419.pdf

Lins, A. P. M., Sichieri, R., Coutinho, W. F., Ramos, E. G., Peixoto, M. V. M., \& Fonseca, V. M. (2013). Alimentação Saudável, escolaridade e excesso de peso entre mulheres de baixa renda. Ciência \& Saúde Coletiva, 18 (2), 357-366. Recuperado de http://www.scielo.br/pdf/csc/v18n2/07.pdf. doi: $10.1590 /$ S1413-81232013000200007

Macedo, T. T. S., Portela, P. P., Palamira, C. S., \& Mussi, F. C. (2015). Percepção de pessoas obesas sobre o seu corpo. Escola Anna Nery, 13(1), 505-510. http://www.scielo.br/pdf/ean/ v19n3/1414-8145-ean-19-03-0505.pdf. doi: 10.5935/1414$\underline{8145.20150067}$

Malta, D. C., Andrade, S. C., Claro, R. M., Bernal, R. T. I., \& Monteiro, C. A. (2014). Evolução anual da prevalência de excesso de peso e obesidade em adultos nas capitais dos 26 estados brasileiros e no Distrito Federal entre 2006 e 2012. Revista Brasileira de Epidemiologia, 17(Supl.1). Recuperado de http://www.scielo.br/pdf/rbepid/v17s1/ pt_1415-790X-rbepid-17-s1-00267.pdf. doi: 10.1590/18094503201400050021

Merleau-Ponty, M. (2011). Fenomenologia da Percepção. Tradução de Carlos Alberto Ribeiro de Moura. (4. ed.) São Paulo: WMF Martins Fontes.
Moraes, J. M., Caregnato, R. C. A., \& Schneider, D. S. (2014). Qualidade de vida antes e depois da cirurgia bariátrica. Acta Paulista de Enfermagem, 27(2), 157-164. Recuperado de http://www.scielo.br/pdf/ape/v27n2/0103-2100ape-27-02-0157.pdf. doi: 10.1590/1982-0194201400028

Pilotto, L. M., Celeste, R. K., Faerstein, E., \& Slavutzky, S. M. B. (2014). Association between tooth loss and overweight/ obesity among Brazilian adults: the Pró-Saúde Study. Brazilian Oral Research, 28(1), 1-6. Recuperado de http:// www.scielo.br/pdf/bor/v28n1/1807-3107bor-28-11807-3107BOR-2014vol280032.pdf. doi: 10.1590/18073107BOR-2014.vol28.0032

Pimenta, F. B. C., Bertrand, E., Mograbi, D. C., Shinohara, H., \& Landeira-Fernandez, J. (2015). The relationship between obesity and quality of life in Brazilian adults. Frontiers in Psychologhy. 6, 966. Recuperado de https://www.ncbi.nlm. nih.gov/pmc/articles/PMC4500922/pdf/fpsyg-06-00966. pdf. doi: $10.3389 /$ fpsyg. 2015.00966

Pinto, F. R. M., \& Silva, C. A. B. (2018). Homens cearenses e obesidade mórbida: perfil e percepções na perspectiva fenomenológica. Anais do Congresso Ibero-Americano em Investigação Qualitativa. Fortaleza, CE, Brasil, 7. Recuperado de https://proceedings.ciaiq.org/index.php/ ciaiq2018/article/view/1823/1775

Rodrigues, A. P. S., \& Silveira, E. A. (2015). Correlação e associação de renda e escolaridade com condições de saúde e nutrição em obesos graves. Ciência \& Saúde Coletiva. 20(1), 165-174. Recuperado de http://www.scielo.br/pdf/csc/ v20n1/1413-8123-csc-20-01-00165.pdf. doi: 10.1590/1413$\underline{81232014201.18982013}$

Sampieri, R. H., Collado, C. F., \& Lucio, M. P. B. (2013). Métodos de Pesquisa. (5.ed.). Porto Alegre: Penso.

SBCBM. Sociedade Brasileira de Cirurgia Bariátrica e Metabólica. Sociedade Brasileira de Cirurgia Bariátrica e Metabólica. Portaria GM/MS 424 e 425/2013. Recuperado de http:// www.sbcbm.org.br/legislacao.php?menu=4

Scherer, P. T. (2015). O peso dos determinantes sociais da saúde na vida dos sujeitos bariátricos (Tese de Doutorado), Pontifícia Universidade Católica do Rio Grande do Sul, Porto Alegre, Rio Grande do Sul, Brasil. Recuperado de http://tede2. pucrs.br/tede2/handle/tede/6496

Silva, P. T., Patias, L. D., Alvarez, G. C., Kirsten, V. R., Colpo, E., \& Moraes, C. M. B. (2015). Perfil de pacientes que buscam a cirurgia bariátrica. $A B C D$. Arquivos Brasileiros de Cirurgia Digestiva, 28(4), 270-273. Recuperdo de http://www.scielo. $\mathrm{br} / \mathrm{pdf} / \mathrm{abcd} / \mathrm{v} 28 \mathrm{n} 4 / \mathrm{pt}$-0102-6720-abcd-28-04-00270.pdf. doi: $10.1590 /$ S0102-6720201500040013 
Souza, M. D. G., Vilar, L., Andrade, C. B., Albuquerque, R. O., Cordeiro, L. H. O., Campos, J. M., \& Ferraz, A A. B. (2015). Obesity prevalence and metabolic syndrome in a park users. $A B C D$. Arquivos Brasileiros de Cirurgia Digestiva, 28(supl. 1), 31-5, 2015. Recuperado de https://www. ncbi.nlm.nih.gov/pmc/articles/PMC4795303/pdf/01026720-abcd-28-s1-00031.pdf. doi: 10.1590/S010267202015005100010

Turi, B. C., Codogno, J. S., Fernandes, R. A., \& Monteiro, H. L. (2014). Prática da atividade física, adiposidade corporal e hipertensão em usuários do Sistema Único de Saúde. Revista Brasileira de Epidemiologia, 17(4), 925-937.

Recuperado de http://www.scielo.br/pdf/rbepid/v17n4/ pt_1415-790X-rbepid-17-04-00925.pdf. doi: 10.1590/18094503201400040011

WHO. World Health Organization. (2006). Obesity and overweight. Recuperado de http://www.mclveganway.org.uk/ publications/who_obesity_and_overweight.pdf 